\title{
Wall Panel Made of Bio-composites
}

\author{
Lukáš Bosák ${ }^{1, *}$, and Milan Palko ${ }^{1}$ \\ ${ }^{1}$ Slovak University of Technology in Bratislava, Faculty of Civil Engineering, Department of \\ Building Construction, Radlinského 11, 81005 Bratislava, Slovak Republic
}

\begin{abstract}
Sustainability is currently an important part of the building industry. The development of new building constructions and the use of ecological materials is a very popular topic in this area. One example of organic material are natural fibres bio-composites. Bio-composite materials are currently used in the form of laminates mainly used in the sport and furniture industries. This article addresses their use in the building industry as the outer envelope of buildings. The article deals with the testing of the influence of UV radiation and moisture on the degradation of Biocomposites with recommendation of possible ways of their protection. In the next section, it deals with the design of composite wall panel with Biocomposite laminates on the top layer. This panel will contain mycelium as thermal insulation. The assumption of the use of this type of construction in the building industry is based on the possibility of replacing conventional materials used nowadays and reducing the environmental load by the building industry. The use of new types of eco-friendly building materials is in accordance with the EU strategy.
\end{abstract}

\section{Biocomposites}

Biocomposite consists of matrix (resin, PLA - Polylactic acid, biodegradable thermoplastic polymer derived from natural renewable sources) and an inner reinforcing layer of natural fibers (obtained from plant stems - mostly Linen, Jute, Flax). The matrix provides the role of the protective casing, preserves the shape of the composite and protects the inner reinforcement. Petrochemical resins are replaced by natural resins or PLA and synthetic fibers (carbon, glass fiber) are replaced by natural fibers (Flax, Linen, Jute). [1]

The samples of the tested biocomposites have a core of woven flax fiber. The test samples are divided as follows: a 1-layer sample of woven flax fiber in natural shade and shade of bordeaux in PLA (polylactic acid) matrix, a 1-layer sample of woven flax fiber in natural shade and shade of bordeaux in PP (polypropylene) matrix and a 3-layer sample of woven flax fiber in natural shade and shade of bordeaux in PLA matrix. The edges of the samples were sealed and samples were placed in test frames (Figure 1). Note: abbreviation L N.PLA.3V 04 means: laboratory tested, natural colour, PLA matrix, 3layers, number of sample

\footnotetext{
* Corresponding author: lukas.bosak@stuba.sk
} 

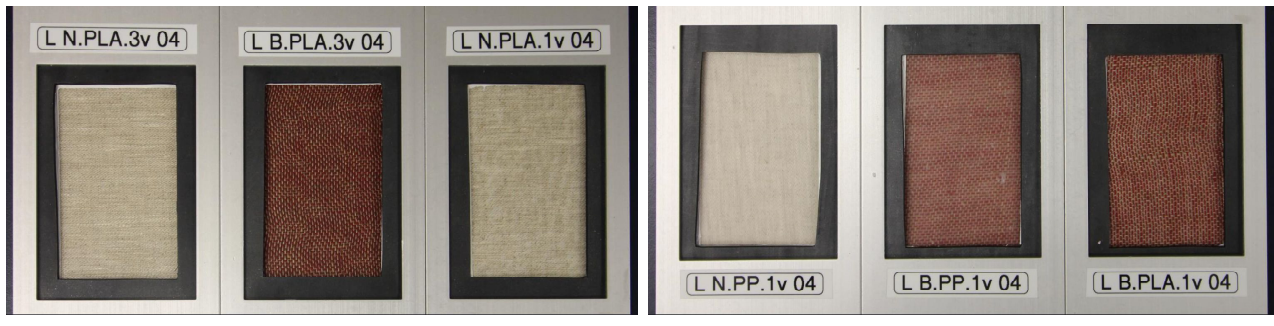

Fig. 1. Biocomposite samples placed in frames.

\section{Sample Testing}

Testing of degradation is performed under laboratory conditions according to STN EN ISO 4892-3: Plastics. Methods of exposure to laboratory light sources. Part 3: Fluorescent UV lamps (ISO 4892-3: 2016). [2] Method A was chosen from Table 4 - Exposure Cycles (Table 1): Accelerated laboratory aging with UVA-340 type fluorescent lamps. From this part was selected cycle no. 2. This cycle corresponds to the standard testing of plastic products.

Table 1. ISO 4892-3: 2016, Table 4 - Exposure cycles.

\begin{tabular}{|c|c|c|c|c|}
\hline \multicolumn{5}{|c|}{ Method A: Artificial accelerated weathering with UVA-340 lamps } \\
\hline $\begin{array}{l}\text { Cycle } \\
\text { No. }\end{array}$ & Exposure period & Lamp type & Irradiance & $\begin{array}{l}\text { Black-panel } \\
\text { temperature }\end{array}$ \\
\hline 1 & $\begin{array}{c}8 \mathrm{~h} \text { dry } \\
4 \mathrm{~h} \text { condensation }\end{array}$ & UVA-340 (type 1A) & $\begin{array}{c}0,76 \mathrm{Wm}^{-2} \times \mathrm{nm}^{-1} \text { at } 340 \mathrm{~nm} \\
\mathrm{UV} \text { lamps off }\end{array}$ & $\begin{array}{l}60^{\circ} \mathrm{C} \pm 3^{\circ} \mathrm{C} \\
50^{\circ} \mathrm{C} \pm 3^{\circ} \mathrm{C}\end{array}$ \\
\hline 2 & $\begin{array}{c}8 \mathrm{~h} \text { dry } \\
0,25 \mathrm{~h} \text { water spray } \\
3,75 \mathrm{~h} \text { condensation }\end{array}$ & $\begin{array}{c}\text { UVA-340 (type } \\
1 \mathrm{~A})\end{array}$ & $\begin{array}{c}0,76 \mathrm{Wm}^{-2} \times \mathrm{nm}^{-1} \text { at } \\
340 \mathrm{~nm} \\
\text { UV lamps off } \\
\text { UV lamps off }\end{array}$ & $\begin{array}{c}50{ }^{\circ} \mathrm{C} \pm 3{ }^{\circ} \mathrm{C} \\
\text { Not controlled } \\
50{ }^{\circ} \mathrm{C} \pm 3{ }^{\circ} \mathrm{C}\end{array}$ \\
\hline 3 & $\begin{array}{c}5 \mathrm{~h} \text { dry } \\
1 \mathrm{~h} \text { water spray }\end{array}$ & UVA-340 (type 1A) & $\begin{array}{c}0,83 \mathrm{Wm}^{-2} \times \mathrm{nm}^{-1} \text { at } 340 \mathrm{~nm} \\
\text { UV lamps off }\end{array}$ & $\begin{array}{l}50^{\circ} \mathrm{C} \pm 3{ }^{\circ} \mathrm{C} \\
\text { Not controlled }\end{array}$ \\
\hline 4 & $\begin{array}{c}5 \mathrm{~h} \text { dry } \\
1 \mathrm{~h} \text { water spray }\end{array}$ & UVA-340 (type 1A) & $\begin{array}{c}0,83 \mathrm{Wm}^{-2} \times \mathrm{nm}^{-1} \text { at } 340 \mathrm{~nm} \\
\text { UV lamps off }\end{array}$ & $\begin{array}{l}70^{\circ} \mathrm{C} \pm 3{ }^{\circ} \mathrm{C} \\
\text { Not controlled }\end{array}$ \\
\hline \multicolumn{5}{|c|}{ Method B: Artificial accelerated weathering with UVA-351 lamps } \\
\hline 5 & $\begin{array}{c}24 \mathrm{~h} \text { dry } \\
\text { (no moisture) }\end{array}$ & UVA-351 (type 1B) & $0,76 \mathrm{Wm}^{-2} \times \mathrm{nm}^{-1}$ at $340 \mathrm{~nm}$ & $50^{\circ} \mathrm{C} \pm 3{ }^{\circ} \mathrm{C}$ \\
\hline \multicolumn{5}{|c|}{ Method C: Artificial accelerated weathering with UVB-313 lamps } \\
\hline 6 & $\begin{array}{c}8 \mathrm{~h} \text { dry } \\
4 \mathrm{~h} \text { condensation }\end{array}$ & UVB-313 (type 2) & $\begin{array}{c}0,48 \mathrm{Wm}^{-2} \times \mathrm{nm}^{-1} \text { at } 310 \mathrm{~nm} \\
\text { UV lamps off }\end{array}$ & $\begin{array}{l}70^{\circ} \mathrm{C} \pm 3{ }^{\circ} \mathrm{C} \\
50^{\circ} \mathrm{C} \pm 3{ }^{\circ} \mathrm{C}\end{array}$ \\
\hline \multicolumn{5}{|c|}{$\begin{array}{l}\text { NOTE } 1 \text { Higher-irradiance tests may be conducted if agreed upon by all interested parties. When high-irradiance conditions } \\
\text { are used, lamp life may be significantly shortened. } \\
\text { NOTE } 2 \text { The } \pm 3{ }^{\circ} \mathrm{C} \text { variation shown for the black-panel temperature is the allowable fluctuation of the indicated black-panel } \\
\text { temperature around the given black-panel temperature set pint under equilibrium conditions. This does not mean that the set } \\
\text { point can vary by } \pm 3^{\circ} \mathrm{C} \text { from the given value. } \\
\text { NOTE } 3 \text { Black-panel temperature during the water spray cycle is not controlled but should not exceed } 30^{\circ} \mathrm{C} \text {. Spray water } \\
\text { temperature might have a significant effect on the result. }\end{array}$} \\
\hline
\end{tabular}

Humidity is a significant factor that affects the properties of natural fibers. The hydroxyl groups $(-\mathrm{OH})$ in the natural fiber cell walls attract moisture (water molecules) and form hydrogen bonds. The natural fiber breaks down and the individual layers degrade due to moisture. Therefore, it can be stated that the most important function in biocomposites is 
the protective matrix. It prevents moisture penetration into the matrix and activates chemical reactions in the fibers, causing their subsequent degradation. In the manufacturing process, hydroperoxide and carbonyl groups of the catalysts can be introduced into the composite. They absorb UV radiation at a wavelength above $290 \mathrm{~nm}$ and trigger photochemical reactions. [3] Photodegradation is caused by a photo-oxidation process that creates cracks in the surface of the composite. Therefore, it is more important to draw attention to the protective layer itself and its degradation due to UV radiation. If it degrades, then we can speak about the degradation of the entire biocomposite. Considering the use of these materials in the building envelope, it would be a biocomposite laminate that would be the top layer of the biopanel. Therefore, these materials need to be tested for the negative effects of the external environment, especially UV radiation.

Testing of these materials is conducted in QUV device. The QUV device (Figure 2) serves to perform accelerated weather tests under laboratory conditions. It simulates the impact of UV radiation in the range of 296-365 $\mathrm{nm}$ and the impact of moisture by condensation and spraying the samples with water, prompting a rapid change in temperature on the test surface of the samples.
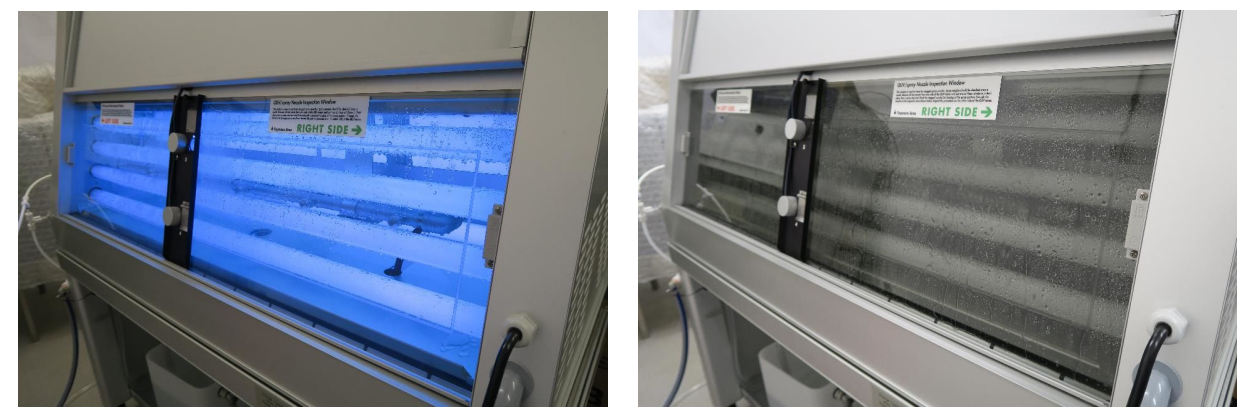

Fig. 2. View of the QUV device (UV period on the left, water spray period on the right)

Total test time was set at $4000 \mathrm{~h}$. One sample of each species was taken after $500 \mathrm{~h}$. There are more results of bio-composite testing. Single-layered samples whose matrix is a PLA layer degrade the fastest. These samples began to degrade after 117 hours in the device. Fig. 3 shows visible damage to single-layer PLA samples exposed to laboratory degradation for $1000 \mathrm{~h}$. After $2000 \mathrm{~h}$, all single-layer PLA samples were removed due to total degradation - the matrix was completely damaged throughout the sample thickness.

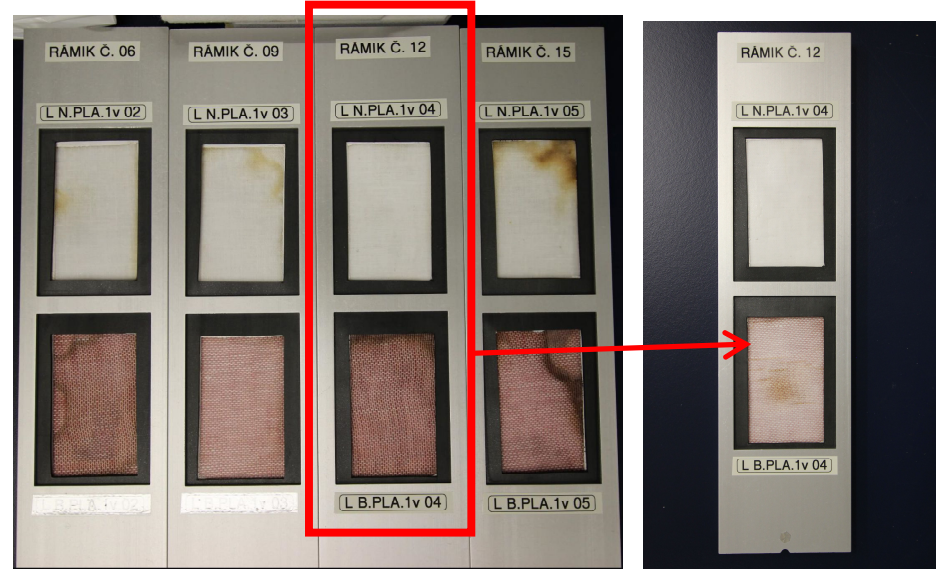

Fig. 3. Degradation of single-layer samples embedded in PLA - after $1000 \mathrm{~h}$ and after $1600 \mathrm{~h}$ 
Multilayer PLA samples and single layer PP samples were more resistant to the thicker coating and did not cause the matrix to break and moisture penetrate to the fibers in the core of the sample. Fig. 4 shows a change in the colour of the sample but no visible damage to the matrix. We can see total degradation of the sample after $3000 \mathrm{~h}$.
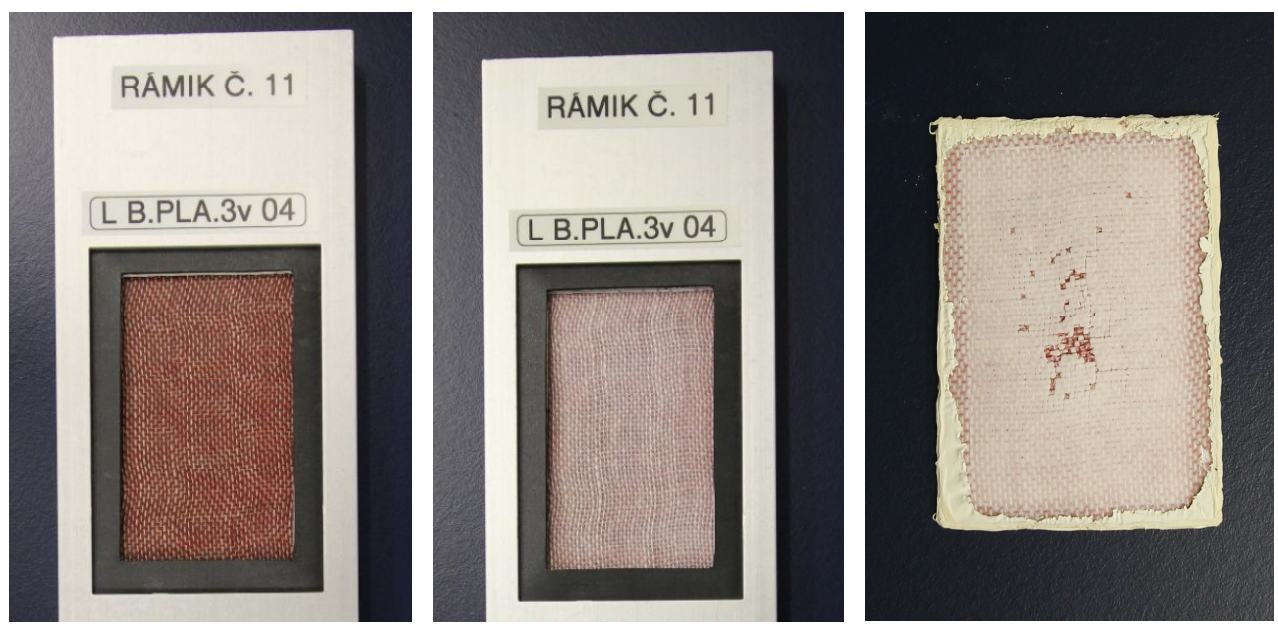

Fig. 4. Visible colour changes of three-layer PLA samples $-170 \mathrm{~h}$ and $300 \mathrm{~h}$ and its total degradation after $3000 \mathrm{~h}$ on the right side.

Research has shown that moisture penetrate into the core of a sample due to defects and imperfections on the surface of the matrix (Figure 5). Imperfections reduce the overall thickness of the biocomposite protective coating and substantially reducing its life. The imperfection is shown in 3D space in Fig. 5, with a total thickness of $136 \mu \mathrm{m}$. We can see crack and degradation of the sample after $2000 \mathrm{~h}$ in Fig. 6.

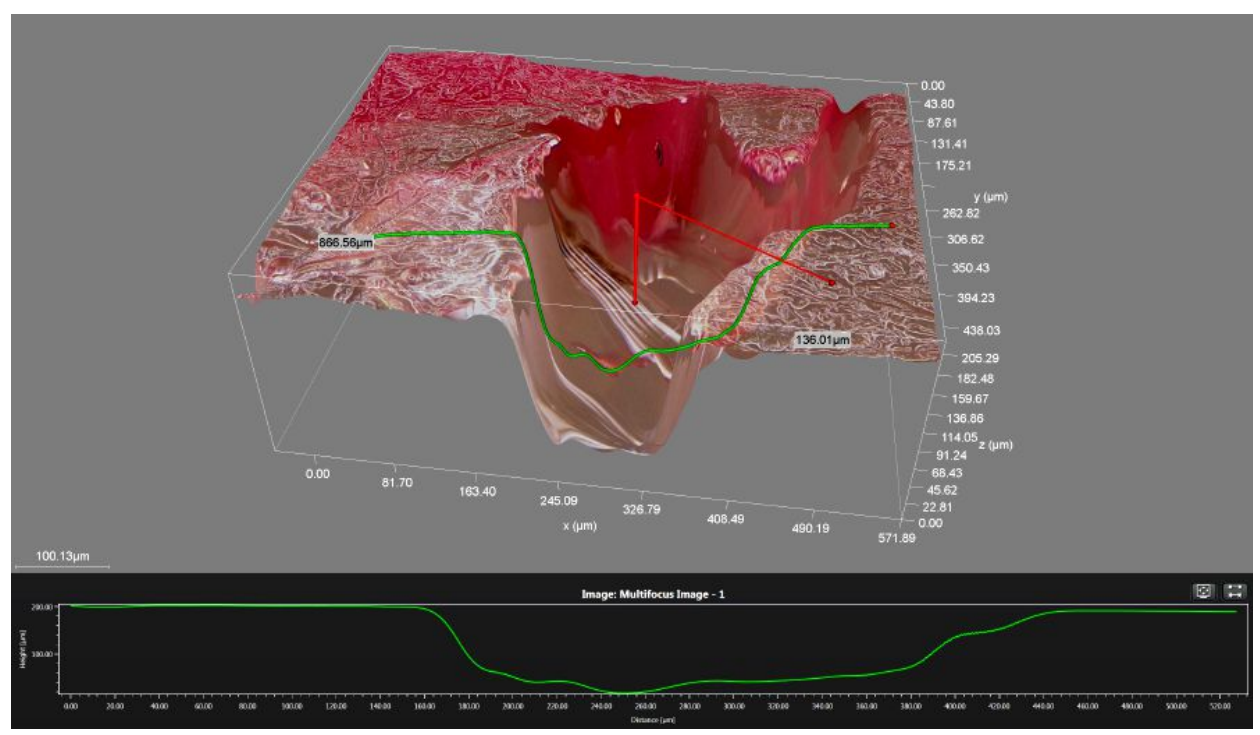

Fig. 5. Imperfection on the surface of PLA samples - under a microscope in 3D space 

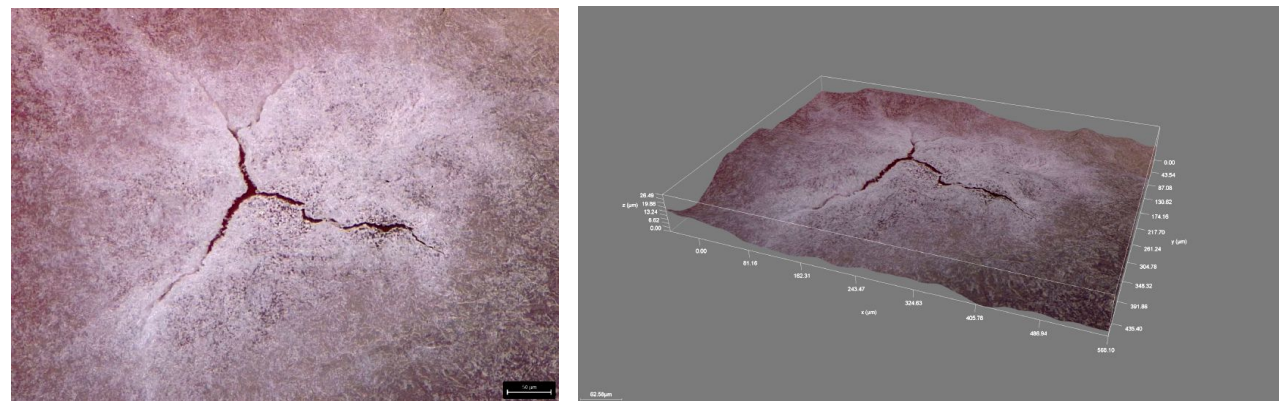

Fig. 6. Crack and degradation of the sample after $2000 \mathrm{~h}$

\section{Wall Panel}

The facade panel will consist of bio-composite laminate exterior shell, a layer of nonwoven flax fibers, mycelium insulation panel and interior shell (Fig. 7). Bio-composites are biodegradable and can be cheaply produced from renewable sources. This is another advantage of biodegradable materials. They are cheaper than conventional materials, which reduces the total cost of exterior coating of buildings.

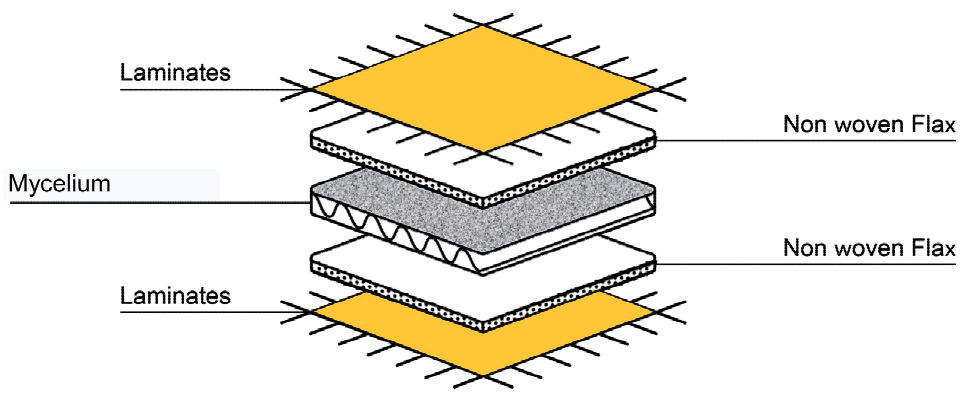

Fig. 7. Layers of future biocomposite wall panel.

Biocomposite wall panel and its parts will be tested in laboratory conditions. First and one of the most important part is thermal insulation. It will consist of mycelium thermal insulation panel. The microscopic branches of mycelium, hyphae, grow outwards into 3D space self-assembling into complex high-performance structures. (Fig.8)
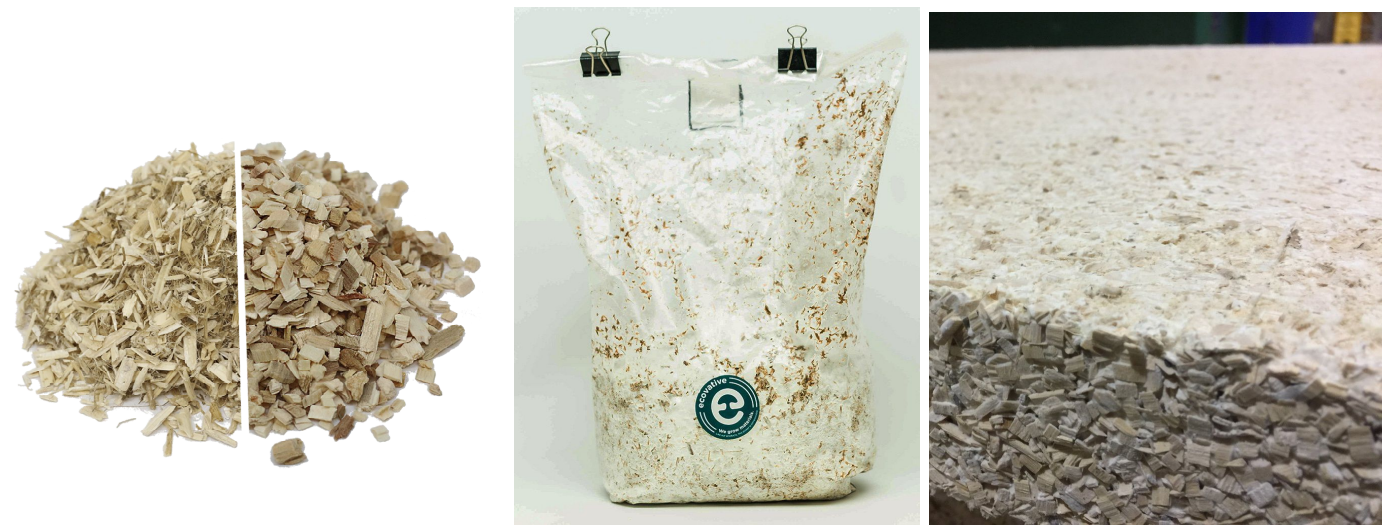

Fig. 8. Process of mycelium growing. Final panel on the right. 
Panels and Blocks are made from aspen wood chips bound with our patented mycelium biomaterial. They are produced using patented biomaterials platform which uses mycelium, a self-assembling biological binder, to grow a lightweight gap filling glue. Panels are cut from large blocks which are grown over the course of 9 days in modified industrial composting infrastructure. [5] These panels will be tested in the climatic chamber to determine their thermo-technical properties.

\section{Conclusion}

Biocomposites will have great potential in the future in the construction industry as the outer envelope of buildings. Based on previous research results, it is advisable to increase the thickness of the top layer of the matrix, or to use multiple layers of PLA. This has to be done to prevent imperfections in the matrix and subsequent degradation of the entire laminate.

The next phase of the research will consist of creating a wall panel prototype consists of bio-composites with thermal insulation from mycelium and its further testing in the climatic chamber.

This research was supported by Scientific Grant Agency MŠVVŠ SR and SAV under VEGA 1/0685/16 and Young Scientist Grant under number 1621.

\section{References}

1. L. Bosák, Civil and Environmental Engineering: 27th Annual PhD Student Conference on Applied Mathematics, Applied Mechanics, Geodesy and Cartography, Landscaping, Building Technology, Theory and Structures of Buildings, Theory and Structures of Civil Engineering Works, Theory and Environmental Technology of Buildings, Water Resources Engineering, 1, 380-387 (Bratislava: Spektrum STU, Slovakia, 2017)

2. L. Yan, N. Chouw, K. Jayaraman, Composites Part B Engineering, 56, 296-317 (2013)

3. STN EN ISO 4892-3: Plastics. Methods of exposure to laboratory light sources. Part 3: Fluorescent UV lamps (ISO 4892-3: 2016)

4. Z. N. Azwa, B. F. Yousif, A. C. Manalo, W. Karunasena, Materials and Design (2012)

5. Ecovative. Our Pilot Plant. Ecovativedesign, Available on: https://ecovativedesign.com/ (2018) 